SAND95-8569 • UC-401

Unlimited Release

Printed July 1995

\title{
Gas-Phase Chemistry During the Conversion of Cyclohexane to Carbon: Flow Reactor Studies at Low and Intermediate Pressure
}

T.H. Osterheld, M.D. Allendorf, R. Larson

\footnotetext{
Prepared by

Sandla National Laboratories

Albuquerque, New Mexico 87185 and Livermore, Califomia 94551

for the United States Department of Energy
}

under Contract DE-AC04-94AL85000

Approved for public release; distribution is unlimited. 
Issued by Sandia National Laboratories, operated for the United States Department of Energy by Sandia Corporation.

NOTICE: This report was prepared as an account of work sponsored by an agency of the United States Government. Neither the United States Government nor any agency thereof, nor any of their employees, nor any of the contractors, subcontractors, or their employees, makes any warranty, express or implied, or assumes any legal llability or responsibility for the accuracy, completeness, or usefulness of any information, apparatus, product, or process disclosed, or represents that its use would not infringe privately owned rights. Reference herein to any specific commercial product, process, or service by trade name, trademark, manufacturer, or otherwise, does not necessarily constitute or imply its endorsement, recommendation, or favoring by the United States Government, any agency thereof or any of their contractors or subconractors. The views and opinions expressed herein do not necessarily state or reflect those of the United States Government, any agency thereof or any of their contractors or subcontractors.

This report has been reproduced from the best available copy.

Available to DOE and DOE contractors from:

Office of Scientific and Technical Information

P.O. Box 62

Oak Ridge TN 37831

Prices available from (615) 576-8401

Available to the public from:

National Technical Information Service

U.S. Department of Commerce

5285 Port Royal Road

Springfield, VA 22161

NTIS price codes

Printed copy: $\mathrm{A03}$

Microfiche copy: A01 


\section{DISCLAIMER}

Portions of this document may be illegible in electronic image products. Images are produced from the best available original document. 
SAND95-8569

Unlimited Release

Printed July 1995

\title{
Gas-Phase Chemistry During the Conversion of Cyclohexane to Carbon: \\ Flow Reactor Studies at Low and Intermediate Pressure*
}

Thomas H. Osterheld, Mark D. Allendorf, and Richard S. Larson

Combustion Research Facility

Sandia National Laboratories

Livermore, CA 94551-0969

\begin{abstract}
The gas-phase branching during the conversion of cyclohexane to solid carbon has been measured in a high-temperature-flow reactor. The experiments show that cyclohexane decomposes into a broad distribution of hydrocarbons that further decompose into the more kinetically stable products hydrogen, methane, acetylene, ethylene, benzene, and PAH. At 1363 $\mathrm{K}$, the evolution to these species occurs quickly. We also observe the buildup of significant amounts of aromatic molecules at later stages in the decomposition, with as much as $15 \%$ of the total carbon in PAH and 25\% in benzene. At later stages, the gas-phase molecules react slowly, even though the system is not at equilibrium, because of their kinetic stability and the smaller radical pool.
\end{abstract}

The decomposition does not appear to depend sensitively on pressure in the regime of 25 to 250 torr. Thus, to a first approximation, these results can be extrapolated to atmospheric pressure.

${ }^{*}$ This work was supported by the DoD Advanced Research Projects Agency 


\section{INTRODUCTION}

Carbon-carbon composites are among the most successful of advanced materials, finding applications ranging from brakes and clutches in aircraft and race cars, to rocket and jet motor components, and even valves in the Jarvik-7 artificial heart. 1,2 These composites have several unique advantages: a very low coefficient of thermal expansion, increasing strength with temperature to over $2500 \mathrm{~K}$, and a high sublimation temperature of over $3500 \mathrm{~K} .{ }^{1}$ Other advantages include their high strength-to-density ratios, high modulus-to-density ratios, good thermal conductivity, and the ability to conduct electricity. ${ }^{1}$

Unfortunately, as with many composite materials, high production costs limit exploitation of their unique properties. A recently developed process for the rapid densification of carbon could reduce production costs. ${ }^{3}$ In this process, the gas-phase precursor cyclohexane $\left(\mathrm{C}_{6} \mathrm{H}_{12}\right)$ is used to densify preforms of carbon fiber woven into a desired shape. Improvement and control of this process requires a better knowledge of the chemical transformation of cyclohexane to solid carbon. In fact, we are not aware of any work characterizing the gas-phase kinetics during this transformation. Previous gas-phase studies of cyclohexane decomposition were motivated by petroleum applications and focused on relatively early stages of the decomposition process. ${ }^{4-13}$ Studies motivated by the materials applications of carbon-carbon composites have generally focused on deposition kinetics or on materials properties such as microstructure. ${ }^{1,2}$ For these non-equilibrium processes, a knowledge of the depositing species and the kinetics of their formation is crucial to attaining an understanding of the deposition process.

As part of a multi-program effort to understand and model chemical vapor deposition processes, this work explores new pyrolysis regimes at very high levels of decomposition under conditions amenable to modeling the reaction chemistry. Specifically, in this paper we report experiments in a high-temperature flow reactor (HTFR), covering the range from low to extremely high levels of decomposition. Experiments at lower temperature $(1160 \mathrm{~K})$ involve reactions of cyclohexane and its primary reaction products and carry the decomposition from low to complete consumption of cyclohexane. Experiments at higher temperature $(1360 \mathrm{~K})$ continue the decomposition of reaction products until the system approaches a quasi-equilibrium of more kinetically stable species. An investigation of the microstructure and deposition kinetics under similar reaction conditions will also be published, along with a detailed kinetic model incorporating a cyclohexane reaction mechanism complete with deposition. ${ }^{14,15}$

In contrast to the short residence-time data obtained in earlier studies, we observe generation of significant amounts of polyaromatic hydrocarbons (PAH). As reaction progresses, extensive dehydrogenation is observed along with the buildup of molecular hydrogen. At the highest temperature and residence time, the major gas-phase species are hydrogen, methane, ethylene, acetylene, and benzene, which account for $99 \%$ of all gas-phase species observed under these conditions. These species react slowly even though the system is far from equilibrium, ${ }^{14}$ due to their kinetic stability and depletion of the pool of reactive radicals present at early stages of the decomposition. Thus, these experiments bridge the gap between the gas-phase and materialsscience work and enable the generation of a simple model of the gas-phase chemistry involved in the deposition of carbon from cyclohexane. ${ }^{14}$ 


\section{EXPERIMENTAL METHODS}

Experimental Configuration and Experimental Conditions. A schematic of the HTFR is shown in Figure 1. Reactions occur within a $100-\mathrm{cm}$ long graphite tube $(5.0 \mathrm{~cm}$ ID) which is enclosed within a water-cooled, insulated vacuum chamber. The reaction tube is oriented vertically with gas flowing from top to bottom. Three independently controlled graphite heating elements surround the tube and heat the gases flowing within it to temperatures up to $1500 \mathrm{~K}$. Reactor pressure is measured and controlled (to \pm 0.1 torr) by a pressure transducer (MKS Instruments) coupled to a throttle valve in the vacuum line. Cyclohexane enters the HTFR through a water-cooled injector and mixes with the preheated carrier gas. The injector is movable, allowing the reactant residence time to be varied with respect to a quartz probe used for sampling.

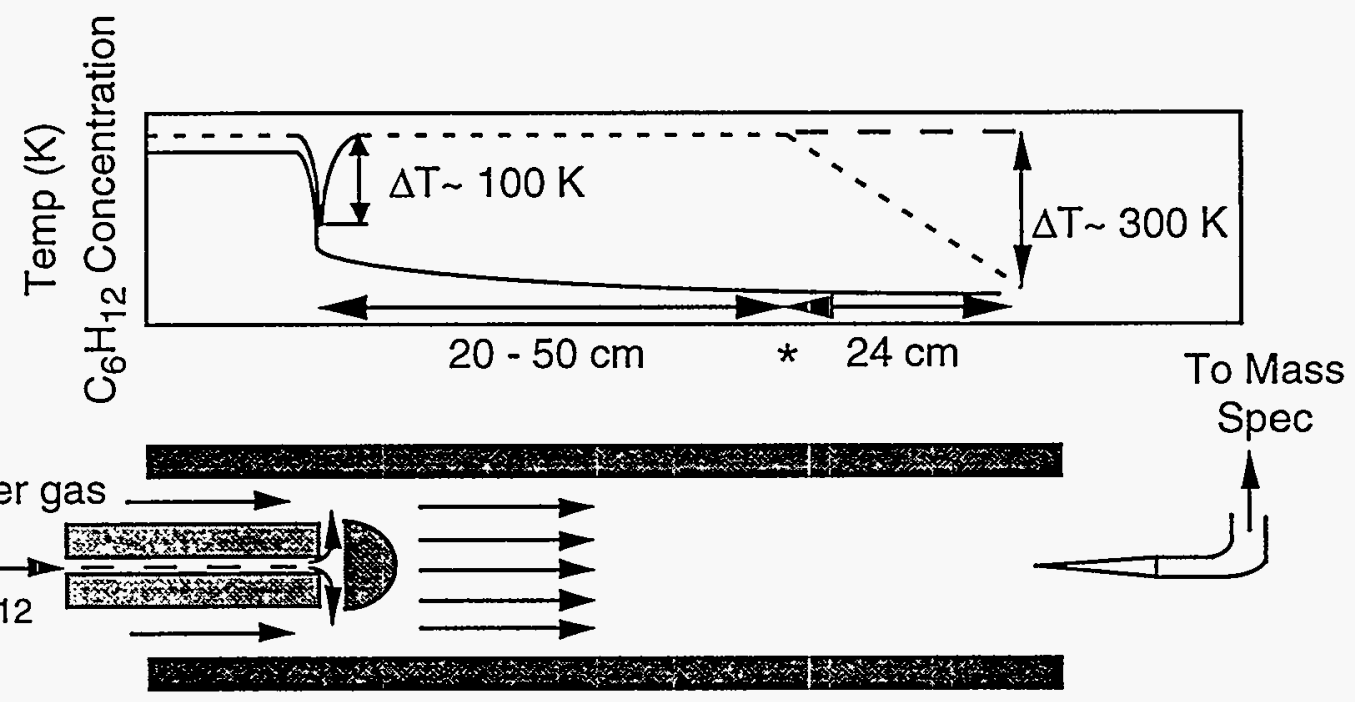

Figure 1. Schematic of high-temperature flow reactor experiment with temperature profile.

Gases are extracted from the HTFR by a quartz sampling probe with a $325-\mu \mathrm{m}$ orifice inserted into the center of the flow in the diagnostic region, defined by the intersection of window ports about $24 \mathrm{~cm}$ downstream of the reactor hot zone. The pressure inside the probe was maintained at $2.0 \pm 0.1$ torr by a pressure transducer/throttle valve combination. Once extracted by the probe, the gases flow past a $200-\mu \mathrm{m}$ orifice attached to an Extrel EXM-500 quadrupole mass spectrometer system where a small portion is expanded into the mass spectrometer for analysis using $70 \mathrm{eV}$ ionization energy. Mass scans up to $250 \mathrm{amu}$ were used to identify decomposition products. Accurate mass calibration was verified by measuring the mass spectrum of perfluorotributylamine. To ensure uniform mass sensitivity, the spectrometer was tuned on a cyclohexane signal to agree with spectra reported in the literature. 
In a typical experiment, helium carrier gas enters the reaction tube and is preheated to the reactor temperature by graphite heat exchangers in contact with the wall adjacent to the first heating element. Cyclohexane is then mixed with the hot carrier gas, following transport to the reactor through the injector. Under the experimental conditions adopted here, both mixing and thermal equilibration of the injected cyclohexane with the preheated carrier gas are rapid compared with the time allowed for reaction to occur. This has been shown by two-dimensional computer simulations of the mixing process. Experiments at $673 \mathrm{~K}$, where cyclohexane does not undergo observable decomposition, also suggest that mixing is fast since the cyclohexane molecular-ion signal is essentially unchanged by moving the injector position from $20.0 \mathrm{~cm}$ to $62.0 \mathrm{~cm}$ from the mass spectrometer probe.

Reactor temperatures were measured with both shielded and unshielded thermocouples, which are inserted into the reactor on the centerline through the injector. A typical temperature profile is included in Figure 1. Radiation effects on measured temperatures were evaluated by obtaining axial temperature profiles using thermocouples of widely different bead sizes $(93 \mu \mathrm{m}$ and $983 \mu \mathrm{m}$ ). The profiles obtained for the two bead sizes were identical to within $\pm 2 \mathrm{~K}$, indicating that the measured temperatures reflect the temperature of the gas. For day-to-day operation, an inconel-shielded thermocouple resides within the injector and can be extended into the flow tube to verify the temperature. For the flow rates used in these experiments, the shape of the temperature profile is unaffected by the flow rate of the carrier gas. A zone of approximately uniform temperature $( \pm 10 \mathrm{~K}$ ) exists between $24 \mathrm{~cm}$ and $62 \mathrm{~cm}$ above the tip of the sampling probe. As shown in Figure 1 (see *), at ca. $24 \mathrm{~cm}$ above the tip of the sampling probe, the temperature in the reactor begins to fall off rapidly (by $\sim 40{ }^{\circ} \mathrm{C}$ in $5 \mathrm{~cm}$ and $\sim 105^{\circ} \mathrm{C}$ in $10 \mathrm{~cm}$ ) because the detection region is unheated. Typically, mass spectra are obtained with three injector locations $(24,43$, and $62 \mathrm{~cm})$ above the sampling probe. In these experiments, flat-zone temperatures of 1163,1263 , and $1363 \mathrm{~K}$ are used with total pressures of 25 and 250 torr and total flow rates of 1.5 and 5 slpm.

Delivery of gases to the reactor is controlled by calibrated mass flow controllers (Tylan or Brooks). To use liquid reactants such as cyclohexane, a temperature-controlled reservoir and mass flow controller system (J. C. Schumacher Co., Carlsbad, CA) is used. Cyclohexane was purchased from Aldrich and has a reported purity of $99.9 \%$. Flow rates of cyclohexane range from $0.03 \mathrm{slpm}$ to $0.07 \mathrm{slpm}$ corresponding to initial cyclohexane concentrations of $1-8 \%$.

Determining Residence Time. The HTFR is used to measure reaction rates and product branching from mass spectrometer measurements as a function of residence time. Residence time is calculated by assuming plug-flow conditions and dividing the distance $(l)$ that the reactant travels by the convective flow velocity $(U)$ (Eq. (1)). ${ }^{16}$ The perfect experiment would vary reactant residence time between zero and the maximum allowed while maintaining a uniform temperature. This ideal is difficult to achieve; thus, several compromises must be made.

$$
\begin{array}{ll}
t_{\text {res }}=l / U \\
U=Q / A & (A=\text { cross-sectional surface area }) \\
& (Q=\text { volumetric flow rate })
\end{array}
$$


First, one cannot obtain data at "zero" residence time because all flow-reactors require a finite time (distance) to allow the reactant to mix with the carrier gas. At these high temperatures, low pressures, and relatively low mass-flow rates (Reynolds numbers $<100$ ), mixing is dominated by diffusion allowing the mixing time to be estimated by Eq. (3). ${ }^{16}$ Data must be obtained with the injector and the sampling probe separated by a distance sufficient for mixing. The mixing length (distance traveled by the reactant before it becomes well-mixed) is given by Eq. (5) after substituting Eq. (4) into Eq. (3). The main result of this complication is that one cannot obtain data at a true zero residence time. However, since lower temperatures should quench thermally activated reactions, we arbitrarily assign a residence time of zero for reactants injected at the point where the temperature starts to drop $(24 \mathrm{~cm}$ above the sampling probe--denoted by a * in Figure 1). Data approaching true zero residence time can be obtained at this location by using low pressures and high flow rates.

$$
\begin{array}{cl}
t_{\text {mix }}=a^{2} /\left(5 D_{c}\right) & (a=\text { tube radius }) \\
t_{\text {mix }}=l_{\text {mix }} / U & (A=\text { cross-sectional surface area }) \\
l_{\text {mix }}=\left(a^{2} U\right) /\left(5 D_{c}\right) & \left(D_{c}=\text { diffusion coefficient }\right)
\end{array}
$$

Second, a complete picture of the decomposition process cannot be obtained from a single experiment, requiring results from several experiments to be pieced together. Thus, to achieve a larger dynamic range in residence time, a series of experiments are usually performed having different flow rates $(Q$ and thus, $U$ ) and pressures $(p)$. For example, total residence time in the reactor tube is shorter at lower pressures and higher flow rates. Experiments under these conditions give good resolution of the behavior at short total residence times while still maintaining a $t_{r e s}$ that is significantly longer than $t_{m i x}$. Alternatively, higher pressures and lower flow rates are used to obtain data at long residence times. Experiments under these conditions provide more extensive decomposition but have poorer (absolute) time resolution and thus will not yield accurate information at short residence time. The results are then combined to yield concentration plots over the entire range of residence times. Two complications can result from this approach. First, reaction rates may be a function of pressure. Second, $t_{m i x}$ in the long residence-time experiments can be large compared to the $t_{\text {res }}$ of the short residence time experiments ( $t_{m i x}$ depends on $p$ because $D_{c}$ is proportional to $1 / p$ ). Thus, it can be difficult to directly overlap data with the same nominal residence time but taken under different reaction conditions.

Lastly, although lower temperatures in the unheated detection region of Sandia's HTFR will quench most thermally activated reactions, some decomposition may still occur. This is unfortunate, since the end of the uniform-temperature region (labeled by a $*$ in Figure 1) is a convenient point to define a "zero residence time" (because the velocity is changing in the detection region, it is difficult to calculate the residence time in this zone). We estimate that in most cases, the amount of decomposition will be small. However, at high temperatures and low flow rates, this factor complicates efforts to combine data sets.

The complications described above are not as serious as they may appear. We use the zero provided by the data with the shortest overall residence time, since it should involve the least reaction in the detection region. Longer residence-time data are then plotted on the same graph, ignoring any data points with residence times shorter than those encountered in the 
experiments at higher $Q$ and lower $p$ which have better temporal resolution. When more rigorous comparison of experiments under different conditions is desired, we follow the common practice of comparing data at similar levels of decomposition.

Data Analysis. To obtain concentrations as a function of residence time, three analog mass spectra were averaged at each injector position and an averaged background spectrum was then removed. The background spectrum was measured immediately before or after a series of measurements using the same reaction conditions but no cyclohexane. The background typically consisted of relatively small peaks from water, nitrogen, turbopump oil ( $\mathrm{m} / \mathrm{z} 44)$, and a large peak at $\mathrm{m} / \mathrm{z} 4$ from the helium carrier gas.

Fragmentation of high-molecular-weight ions provides the main complication when using mass spectrometric product detection, yielding signals that may overlap with those of other species. To minimize such interference we developed the following analysis method. Beginning with the peak for the highest observed mass, we identified products by making comparisons with literature mass spectra from Cornu and Massot's compilation. ${ }^{17}$ Identification was particularly straightforward for aromatic species since the molecular ion (M) and $M-1$ ion are usually the largest peaks in their spectra. However, it was not always possible to distinguish between structural isomers (such as anthracene and phenanthrene) with this method. The contribution to the spectrum measured in the HTFR for each species identified was then removed by normalizing the reported fragmentation pattern to a characteristic ion signal (usually $M$ or $M-1$ ) and then subtracting this from the measured spectrum. By starting the subtraction process at the highest mass signal and sequentially working toward lower molecular weight species, the contributions to the lower mass signals from fragments of higher molecular weight species can be removed. This allows signals for most species to be observed without interference. For example, styrene has a parent ion signal at $104 \mathrm{amu}$ while benzene's parent ion signal is at 78 amu. But styrene also has a fragment ion producing a signal at $\mathrm{m} / \mathrm{z} 78$ that is about $32 \%$ of its 104-amu peak. If a signal is observed at $\mathrm{m} / \mathrm{z} 104$ of 1.0 (arbitrary units) from styrene, then subtraction of 0.32 from the signal at $\mathrm{m} / \mathrm{z} 78$ yields the parent ion signal at $\mathrm{m} / \mathrm{z} 78$ for benzene. The lack of isomeric structural information can produce some error, since two structural isomers may not have identical spectra. However, most of the isomers of hydrocarbons encountered in this study have similar spectra. ${ }^{17}$

Absolute concentrations were not determined because long-term changes in the size of the probe orifice from buildup of carbon deposits affected instrument sensitivity. Overlapping signals also prevented the use of an internal standard such as argon. Product abundances relative to n-butane were determined from characteristic ion signals by using the standard ratios reported in Cornu and Massot's compilation to correct for differences in sensitivity. ${ }^{17}$ The compilation provides the ratio of the largest peak in a mass spectrum to that of the largest peak of n-butane $(\mathrm{m} / \mathrm{z} 43)$ when the two are in equal abundance.

This experimental method differs from those used previously for the detection of hydrocarbon species in flames. ${ }^{18}$ In those experiments, lower electron energies were used for the ionization process. Our current experimental configuration does not allow us to use lower electron energies. However, our method is advantageous in that it allows experimental data to be compared with literature spectra taken at the standard $70 \mathrm{eV}$ conditions, making quantitative 
measurement of abundances much simpler. The disadvantage arises in the more extensive fragmentation which complicates the analysis.

The mass spectrometer used here does not provide uniform mass sensitivity to very low amu. Thus, the signal levels at 2-4 amu were much lower than those measured at higher mass. This decreases the accuracy of measured hydrogen concentrations because the low sensitivity at $2 \mathrm{amu}$ amplifies any error. To obtain accurate hydrogen abundances (relative to the other species), we calibrated its signal to that of cyclohexane using known flow rates of both species.

\section{RESULTS AND DISCUSSION}

Product Branching. The 29 different products detected in the pyrolysis of cyclohexane are shown in Figure 2. Although Figure 2 shows molecular structures, as noted above, mass spectrometric detection actually provides only the atomic formula. The structures in Figure 2 are those most consistent with the expected reaction mechanism ${ }^{14}$ and/or the most stable structures 19 for a given atomic formula. Most of the detected species are significantly unsaturated (dehydrogenated) indicating that dehydrogenation reactions are important in the pyrolysis process. In fact, the only saturated hydrocarbons observed as products are methane and ethane. Notice that a broad distribution of $\mathrm{PAH}$, from $\mathrm{C}_{6}$ to $\mathrm{C}_{14}$, is also observed and that all of the species with more than 6 carbon atoms use benzene as a building block.

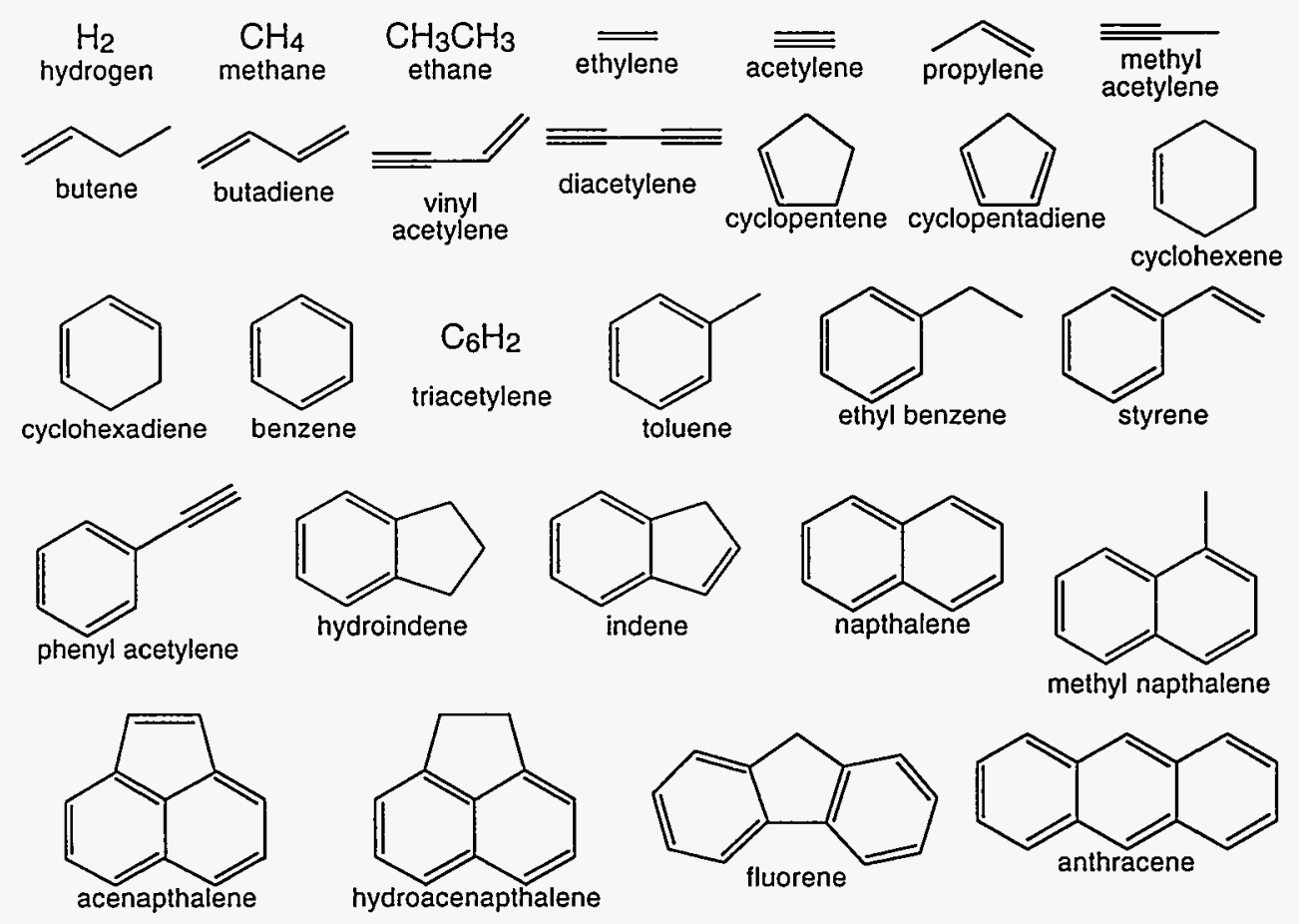

Figure 2. Products identified in the pyrolysis of cyclohexane. Structures may not be accurate (see text). 
Figure 3 displays a representative mass spectrum obtained at $1163 \mathrm{~K}$ and at a residence time of $\tau=1.2 \mathrm{~s}$. The signal-to-noise ratio is quite good and peaks are observed from $\mathrm{m} / \mathrm{z} 2$ to 166 , spanning the molecular weights of molecules from hydrogen to fluorene. The small negative peaks at $\mathrm{m} / \mathrm{z} 4$ and 18 arise from the background subtraction of the helium carrier gas and water present in the mass spectrometer vacuum chamber. As one can see, the major products observed are benzene $(\mathrm{m} / \mathrm{z} 78)$, ethylene $(\mathrm{m} / \mathrm{z} 28$ and 26$)$, acetylene $(\mathrm{m} / \mathrm{z} 26)$ and methane $(\mathrm{m} / \mathrm{z}$ 16 and 15). To more clearly display the signals for the PAH compounds, the inset shows a blowup of the region from 80 to $170 \mathrm{amu}$. For these species, the major signals are for toluene $(\mathrm{m} / \mathrm{z} 91$ and 92), phenyl acetylene $(\mathrm{m} / \mathrm{z} 102)$, styrene $(\mathrm{m} / \mathrm{z} 104)$, indene $(\mathrm{m} / \mathrm{z} 115$ and 116$)$, and naphthalene ( $\mathrm{m} / \mathrm{z} 128)$.

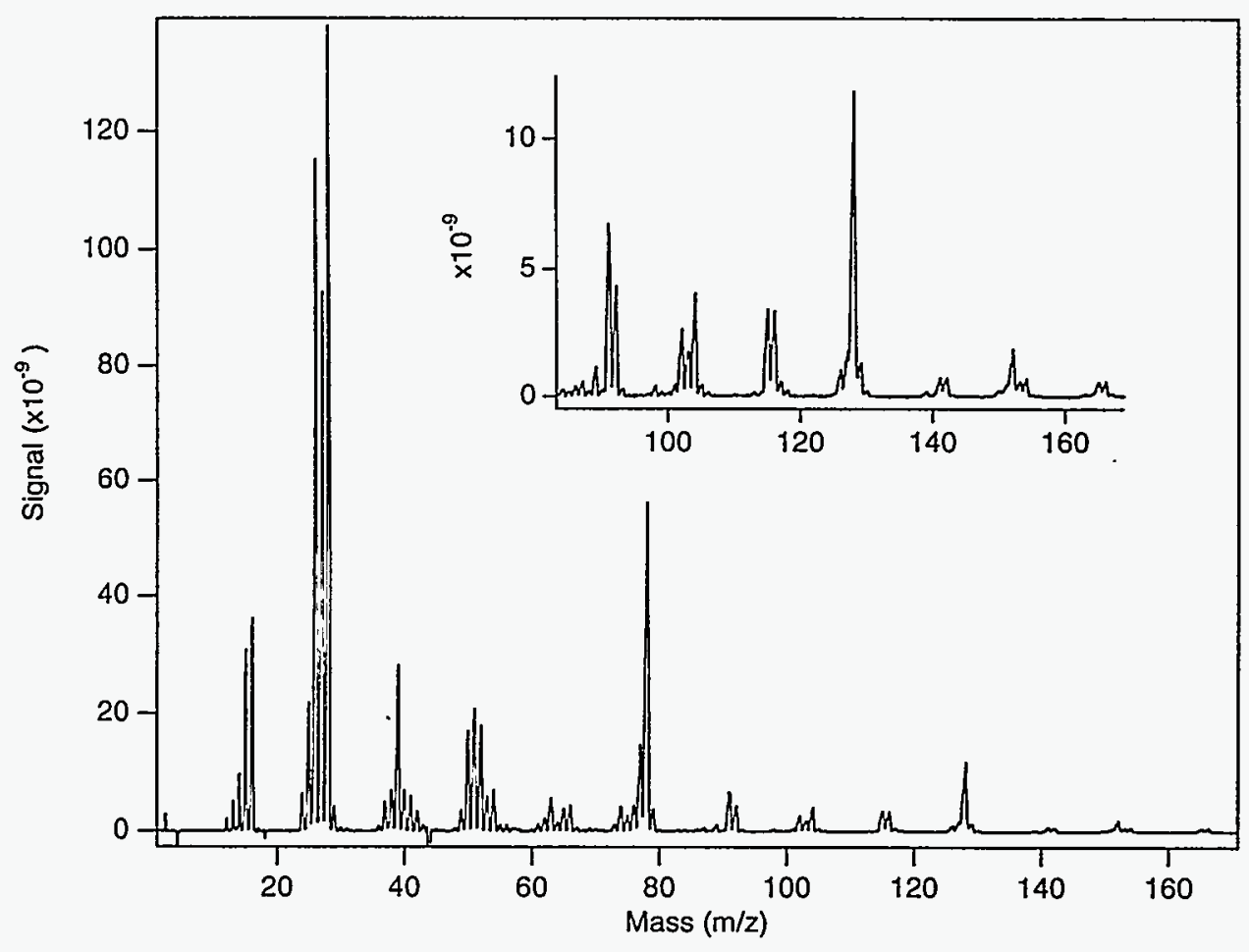

Figure 3. Representative spectrum at $1163 \mathrm{~K}, 250$ torr, and $1.2 \mathrm{~s}$ residence time.

Table I provides product branching information as a function of residence time, temperature, and pressure. The concentrations are given as mole fractions (expressed as percentages) and are calculated by taking the abundance of a given species and dividing it by the sum of abundances at the same residence time. For clarity, several species are omitted that do not reach significant concentrations on the time scales of our experiments (e.g. cyclopentene) or were only present at short residence time (e.g. butene). Thus, the sum of any row in Table I will not add up to $100 \%$. 
Table I. Percent concentrations of selected species.

\begin{tabular}{|c|c|c|c|c|c|c|c|c|c|c|c|c|c|c|c|}
\hline $\begin{array}{c}\text { Temp } \\
\text { (K) }\end{array}$ & $\begin{array}{c}\tau \\
\text { (sec) }\end{array}$ & $\begin{array}{c}P \\
\text { (torr) }\end{array}$ & PAH & $\mathrm{C}_{10} \mathrm{H}_{8}$ & $\mathrm{C}_{6} \mathrm{H}_{12}$ & $\mathrm{C}_{6} \mathrm{H}_{6}$ & $\mathrm{C}_{4} \mathrm{H}_{6}$ & $\mathrm{C}_{4} \mathrm{H}_{4}$ & $\mathrm{C}_{4} \mathrm{H}_{2}$ & $\mathrm{C}_{3} \mathrm{H}_{6}$ & $\mathrm{C}_{3} \mathrm{H}_{4}$ & $\mathrm{C}_{2} \mathrm{H}_{4}$ & $\mathrm{C}_{2} \mathrm{H}_{2}$ & $\mathrm{CH}_{4}$ & $\mathrm{H}_{2}$ \\
\hline \multirow[t]{12}{*}{1163} & 0.09 & 27.4 & 0 & 0 & 33.0 & 1.1 & 16.7 & 1.1 & 0.6 & 4.8 & 5.7 & 28.1 & 0 & 3.2 & $\mathrm{n} / \mathrm{a}$ \\
\hline & 0.04 & 5 slpm & 0 & 0 & 61.5 & 0.6 & 8.2 & 0.7 & 0.4 & 3.2 & 3.1 & 19.7 & 0 & 0.9 & $\mathrm{n} / \mathrm{a}$ \\
\hline & 0 & & 0 & 0 & 100 & 0 & 0 & 0 & 0 & 0 & 0 & 0 & 0 & 0 & $n / a$ \\
\hline & 0.24 & 25.5 & 0.8 & 0.1 & 4.6 & 3.2 & 15.0 & 2.8 & 0.8 & 7.1 & 5.4 & 34.9 & 3.6 & 6.9 & 11.3 \\
\hline & 0.12 & $1.5 \mathrm{slpm}$ & 0.3 & 0 & 19.1 & 1.7 & 16.3 & 1.5 & 0.5 & 4.5 & 5.0 & 26.8 & 1.4 & 4.9 & 10.9 \\
\hline & $\mathbf{0}$ & & 0 & 0 & 100 & 0 & 0 & 0 & 0 & 0 & 0 & 0 & 0 & 0 & 0 \\
\hline & 0.71 & 250 & 1.7 & 0.5 & 0 & 6.8 & 5.4 & 2.8 & 0.8 & 1.6 & 2.7 & 47.5 & 8.2 & 11.6 & 8.4 \\
\hline & 0.36 & 5 slpm & 1.3 & 0.2 & 5.1 & 4.5 & 14.3 & 2.9 & 0.4 & 4.1 & 3.0 & 40.0 & 4.6 & 7.4 & 8.7 \\
\hline & 0 & & 0 & 0 & 63.1 & 0 & 6.1 & 0.4 & 0 & 0 & 1.2 & 11.5 & 0 & 1.5 & 5.1 \\
\hline & 2.38 & 250 & 4.2 & 1.8 & 0 & 10.7 & 1.1 & 2.1 & 0.8 & 0.9 & 0.4 & 43.9 & 8.2 & 15.6 & 11.8 \\
\hline & 1.19 & $1.5 \mathrm{slpm}$ & 4.2 & 1.3 & 0 & 10.5 & 3.3 & 2.4 & 0.5 & 2.3 & 1.1 & 45.1 & 6.0 & 13.2 & 10.6 \\
\hline & 0 & & 0.4 & 0.04 & 38.0 & 2.4 & 16.6 & 1.2 & 0.8 & 4.3 & 1.7 & 20.2 & 1.0 & 4.4 & 7.2 \\
\hline \multirow[t]{12}{*}{1263} & 0.07 & 27.8 & 0.6 & 0 & 0.4 & 2.6 & 7.2 & 3.6 & 0.6 & 4.6 & 6.3 & 40.2 & 10.1 & 7.4 & 13.5 \\
\hline & 0.03 & 5 slpm & 0.3 & 0 & 3.0 & 1.7 & 12.0 & 2.8 & 0.6 & 6.2 & 6.9 & 39.0 & 4.4 & 6.0 & 13.4 \\
\hline & 0 & & 0.1 & 0 & 35.2 & 0.6 & 10.5 & 0.6 & 0.5 & 4.3 & 3.6 & 25.7 & 0 & 2.6 & 11.8 \\
\hline & 0.23 & 26.4 & 3.4 & 0.9 & 0 & 8.3 & 1.8 & 3.5 & 1.0 & 1.4 & 1.9 & 38.9 & 14.1 & 12.8 & 12.4 \\
\hline & 0.12 & $1.5 \mathrm{slpm}$ & 2.8 & 0.5 & 0 & 7.0 & 5.0 & 4.1 & 0.9 & 3.1 & 3.2 & 38.4 & 10.1 & 11.3 & 12.9 \\
\hline & 0 & & 0.7 & 0.1 & 11.9 & 2.8 & 15.3 & 2.1 & 0.6 & 6.0 & 3.9 & 27.9 & 2.8 & 6.6 & 15.3 \\
\hline & 0.66 & 250 & 1.8 & 0.6 & 0 & 7.6 & 0 & 1.0 & 0.8 & 0.7 & 0.3 & 32.2 & 26.0 & 12.4 & 17.0 \\
\hline & 0.32 & $5 \mathrm{slpm}$ & 2.1 & 0.6 & 0 & 6.1 & 0 & 1.0 & 0.1 & 0.9 & 1.0 & 42.0 & 17.0 & 13.2 & 16.6 \\
\hline & 0 & & 1.3 & 0.2 & 2.2 & 4.3 & 10 & 3.7 & 0.9 & 1.7 & 3.5 & 43.2 & 8.1 & 7.7 & 10.1 \\
\hline & 2.19 & 250 & 1.2 & 0.7 & 0 & 6.0 & 0 & 0.8 & 0.4 & 0.6 & 0.1 & 10.8 & 12.7 & 18.2 & 49.2 \\
\hline & 1.10 & 1.5 slpm & 1.5 & 0.9 & 0 & 6.8 & 0 & 1.2 & 0.5 & 0.7 & 0.2 & 20.0 & 14.0 & 19.4 & 35.8 \\
\hline & 0 & & 2.4 & 0.9 & 0 & 6.3 & 0 & 1.7 & 0.4 & 1.2 & 0.7 & 38.1 & 8.3 & 15.3 & 23.7 \\
\hline \multirow[t]{12}{*}{1363} & 0.07 & 26.1 & 1.0 & 0.2 & 0 & 4.3 & 0.7 & 2.8 & 1.1 & 1.4 & 2.3 & 39.1 & 25.1 & 9.6 & 12.7 \\
\hline & 0.04 & $5 \mathrm{sipm}$ & 0.9 & 0.2 & 0 & 3.5 & 1.9 & 3.5 & 0.9 & 2.3 & 3.6 & 41.0 & 18.3 & 8.5 & 15.5 \\
\hline & 0 & & 0.5 & 0.1 & 0 & 2.2 & 6.9 & 3.8 & 0.6 & 2.3 & 6.4 & 41.1 & 10.5 & 7.2 & 15.9 \\
\hline & 0.23 & 26.0 & 1.4 & 0.6 & 0 & 5.7 & 0 & 1.1 & 1.0 & 0 & 0.5 & 21.9 & 27.8 & 10.6 & 30 \\
\hline & 0.12 & $1.5 \mathrm{slpm}$ & 1.6 & 0.6 & 0 & 6.0 & 0 & 1.5 & 0.9 & 0.5 & 0.8 & 28.2 & 23.3 & 11.0 & 26.2 \\
\hline & 0 & & 1.4 & 0.3 & 0 & 5.2 & 1.2 & 2.7 & 0.8 & 1.4 & 2.2 & 33.2 & 16.1 & 10.3 & 25.6 \\
\hline & 0.61 & 250 & 0.3 & 0.1 & 0 & 2.9 & 0 & 0.5 & 0.4 & 0 & 0 & 4.9 & 33.9 & 10.8 & 46.1 \\
\hline & 0.31 & 5 slpm & 0.5 & 0.2 & 0 & 3.7 & 0 & 0.8 & 0.5 & 0 & 0 & 12.7 & 33.1 & 12.6 & 36.1 \\
\hline & 0 & & 0.9 & 0.3 & 0 & 4.4 & 0 & 1.4 & 0.6 & 0.7 & 0.8 & 35.0 & 21.1 & 13.3 & 21.9 \\
\hline & 2.03 & 250 & 0.2 & 0.1 & 0 & 2.2 & 0 & 0.3 & 0.2 & 0.7 & 0 & 3.0 & 7.2 & 11.7 & 74.6 \\
\hline & 1.02 & $1.5 \mathrm{slpm}$ & 0.4 & 0.2 & 0 & 3.2 & 0 & 0.5 & 0.2 & 0.7 & 0 & 4.3 & 10.7 & 12.7 & 67.3 \\
\hline & 0 & & 1.3 & 0.7 & 0 & 5.2 & 0 & 1.1 & 0.3 & 0.8 & 0.2 & 16.0 & 16.0 & 15.3 & 43.8 \\
\hline
\end{tabular}

The decomposition and formation of primary products (and cyclohexane) is shown in Figures 4 and 5. These figures are derived from the data in Table I and show the dependence on residence time of the relative concentration of the major constituents at $1163 \mathrm{~K}$. Data points to the left of the dashed line in the figure were obtained at ca. 25 torr total pressure, while those to the right were obtained at ca. 250 torr. By a residence time of $0.7 \mathrm{~s}$, the concentration of cyclohexane has dropped to zero, while ethylene has become the dominant constituent. At the same time, methane, acetylene, benzene, naphthalene, and PAH are increasing in concentration. Butadiene, propylene, methyl acetylene, and vinyl acetylene show behavior characteristic of intermediates, with concentrations that peak at ca. $0.1-0.3 \mathrm{~s}$ and then drop, almost monotonically, to much lower levels. Notice the relatively high concentration of PAH (we define PAH to refer to any aromatic species other than benzene). If the PAH contribution to total carbon is considered, the yield is substantial. For example, at $1163 \mathrm{~K}$ and $\tau=2.4 \mathrm{~s}$, PAH contain ca. $16 \%$ of the total gas-phase carbon. 


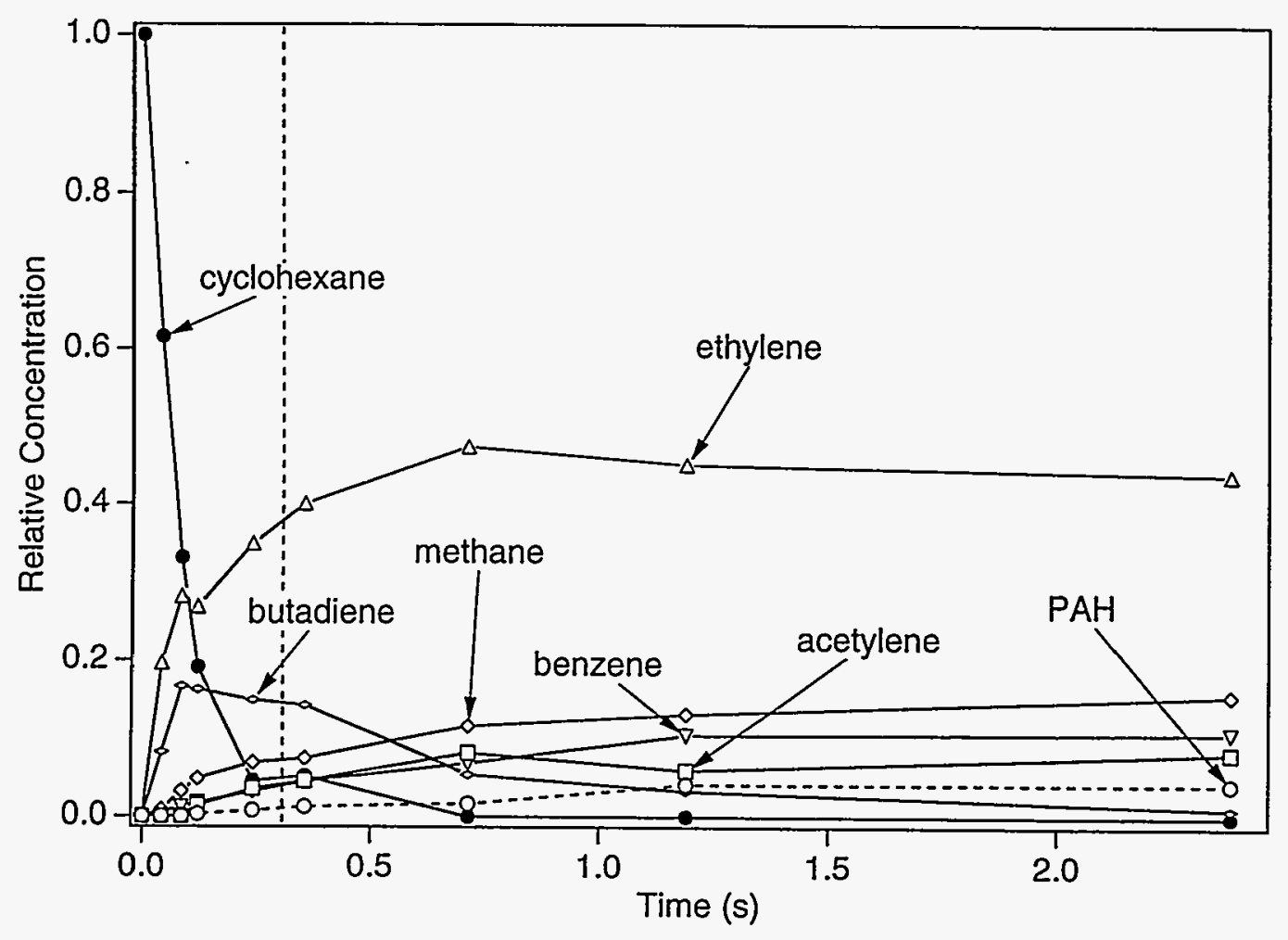

Figure 4. Dependence of the relative concentration of major constituents on residence time at $1163 \mathrm{~K}$.



Figure 5. Dependence of the relative concentration of minor constituents on residence time at $1163 \mathrm{~K}$. 
At higher temperatures, reaction progresses beyond cyclohexane decomposition to the decomposition of initially-formed species. Figure 6 shows the dependence on residence time of the relative concentration of the major constituents at $1363 \mathrm{~K}$. Notice that cyclohexane is not observed because it decomposes too quickly, even at the temperatures encountered in the detection region. In contrast to Figure 4, ethylene now seems to behave like an intermediate, starting as the major constituent at short residence time and then dropping to low concentrations at long residence time. Acetylene also behaves like an intermediate species, achieving much higher concentrations than those observed in Figure 4 and passing through a maximum at ca. 0.6 s. Methane, benzene, and PAH slightly increase in concentration and then stay relatively constant over the longer residence times, while hydrogen grows dramatically and becomes the dominant species at long residence time, with concentrations much higher than those observed in Figure 4 at $1163 \mathrm{~K}$.

Gas-Phase Kinetics. Under conditions giving the highest extent of reaction $(1363 \mathrm{~K}$, $\tau=2.0 \mathrm{~s}$ ), benzene, ethylene, acetylene, methane, and hydrogen compose about $99 \%$ of the gasphase products (Table I and Figure 6). At the same time, it is apparent from Figure 6 that reactivity decreases at the longer residence times since the relative concentrations remain fairly constant. Thus, the system has evolved from twenty nine species in the initial stages to five molecules that are reacting slowly. At these temperatures and residence times, the system is not at equilibrium. ${ }^{14}$ However, these five species remain because: (1) they have relatively high kinetic stability under the reaction conditions and (2) the pool of larger and reactive (nonaromatic and hydrogenated) hydrocarbons that can initiate or propagate radical chains has been depleted, further decreasing the rate at which the five species can decompose.

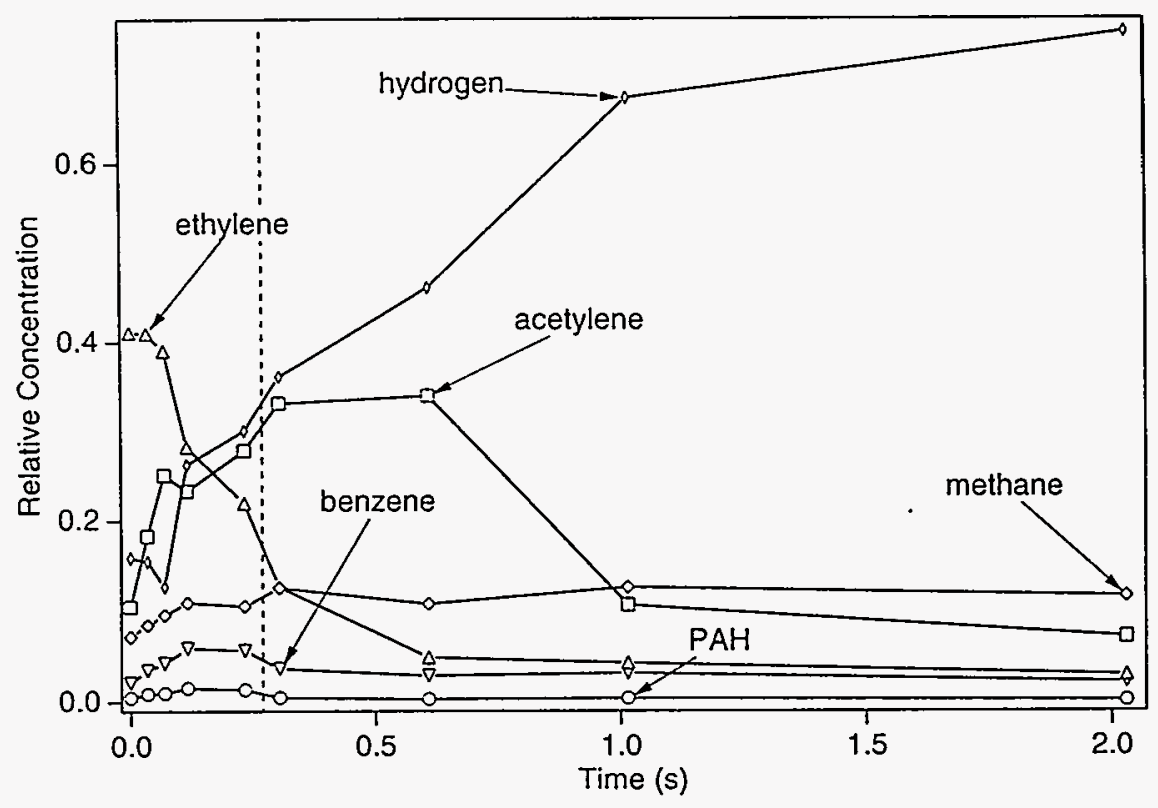

Figure 6. Dependence of the relative concentration of major constituents on residence time at $1363 \mathrm{~K}$. 
The relatively smooth transition between 25 and 250 torr displayed in Figures 4-6 shows that pressure effects are not dramatic even for the primary decomposition of cyclohexane. This is evident from the transition through the vertical dashed line that separates the data taken at the two different pressures. In essentially all cases the concentration curves pass through this transition smoothly. The effect of pressure on product branching can be further evaluated by comparing data under similar levels of decomposition (Figure 7). As mentioned earlier, comparing product branching data in this fashion is a common practice in flow reactor experiments. For example, at $1163 \mathrm{~K}, 95.4 \%$ of the cyclohexane decomposed at 25.5 torr and $\tau \sim 0.24 \mathrm{~s}$ while $94.9 \%$ of the cyclohexane decomposed at 250 torr and $\tau \sim 0.36 \mathrm{~s}$ (Table I). As shown in Figure 7, the higher pressure appears to facilitate the formation of $\mathrm{PAH}$, benzene $\left(\mathrm{C}_{6} \mathrm{H}_{6}\right)$, ethylene, $\left(\mathrm{C}_{2} \mathrm{H}_{4}\right)$, and acetylene $\left(\mathrm{C}_{2} \mathrm{H}_{2}\right)$. At the same time, the concentrations of propylene $\left(\mathrm{C}_{3} \mathrm{H}_{6}\right)$ and methyl acetylene $\left(\mathrm{C}_{3} \mathrm{H}_{4}\right)$ decrease. These observations are consistent with increased decomposition rates at higher pressures, since the concentrations of PAH, benzene, ethylene, and acetylene increase with residence time in Figure 4 (at the shorter residence times), while intermediate species such as propylene and methyl acetylene decrease (after an early maximum). This may arise from increases in unimolecular reaction rates, which are pressure dependent, or from faster bimolecular reactions due to the higher (absolute) concentrations of reactants. However, it is important to note that, in all cases, the effect is small. This latter observation is not meant to exclude the possibility that pressure affects the unimolecular reaction rates in this system. In fact, a detailed examination of the combustion literature would identify many reactions in this system that are in their pressure falloff region (meaning that they have a pressure dependence). However, the dependence appears to be relatively weak for the major constituents in the system. This experimental observation demonstrates that to a first approximation it should be straightforward to extrapolate the data obtained from these experiments to atmospheric pressure with relatively minimal error.

Experiments designed to separate the influence of concentration from the influence of pressure were less conclusive but appeared to favor more decomposition at higher concentrations. These experiments were conducted to separate the effects of a 10-fold increase in pressure from the concomitant 10-fold increase in (absolute) concentration of the reactants. Experiments were conducted at $1263 \mathrm{~K}$ and 26.4 torr for residence times of up to $0.23 \mathrm{~s}$, using initial concentrations of $2 \%$ and $6 \%$ cyclohexane. The results for a $0.23-\mathrm{s}$ residence time are shown in Figure 8. More PAH and less acetylene and methyl acetylene were observed at the higher concentration. Other experiments (not shown) also exhibited a slight preference for benzene at the higher concentrations. The increases in PAH and benzene and decrease in methyl acetylene are consistent with more extensive decomposition at higher concentrations (as discussed in the preceding paragraph). However, the decrease in acetylene is not consistent since higher acetylene concentrations are expected with more extensive decomposition (Figures 4 and 6). The decrease in acetylene concentration may be an artifact arising from errors in the subtraction procedure used in analysis, since many higher molecular weight species yield an $\mathrm{m} / \mathrm{z}$ 26-fragment in their mass spectrum. This experiment was also conducted early in the study when the spectrometer had a much larger nitrogen background, further complicating the background subtraction in the 26-28 amu range. However, it is again apparent from Figure 8 that most species were not substantially affected by the change in concentration. 


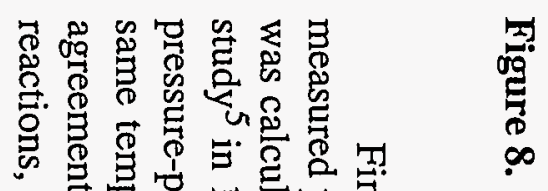

它完它宫

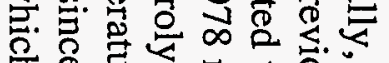

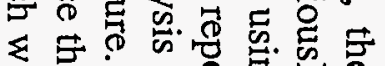

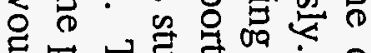

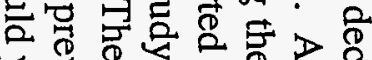

৬.

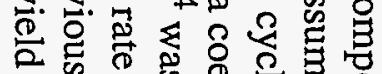

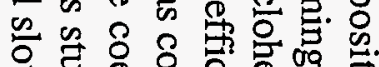

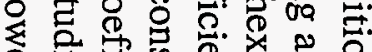

象家.

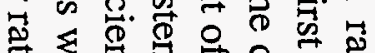

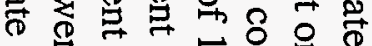



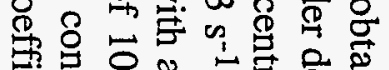

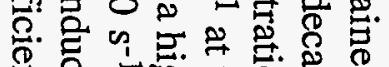


2 专的的办

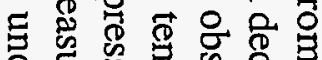
क 8 응 응 ते दृ 윰

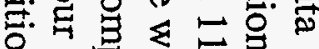

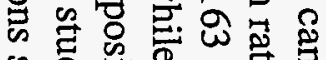



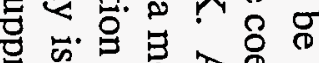



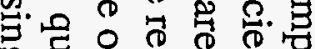

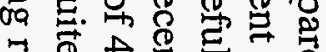

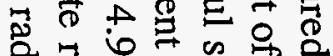
त्वृ

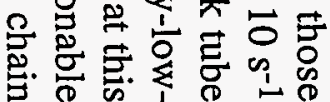

承



$\stackrel{4}{9}$






\section{SUMMARY}

The gas-phase branching during the conversion of cyclohexane to solid carbon has been measured in a high-temperature-flow reactor. The experiments show that cyclohexane decomposes into a broad distribution of hydrocarbons that further decompose into the more kinetically stable products hydrogen, methane, acetylene, ethylene, benzene, and PAH. At 1363 $\mathrm{K}$, the evolution to these species occurs quickly. We also observe the buildup of significant amounts of aromatic molecules at later stages in the decomposition, with as much as $15 \%$ of the total carbon in PAH and 25\% in benzene. At later stages, the gas-phase molecules react slowly, even though the system is not at equilibrium, because of their kinetic stability and the smaller radical pool.

The decomposition does not appear to depend sensitively on pressure in the regime of 25 to 250 torr. Thus, to a first approximation, these results can be extrapolated to atmospheric pressure.

\section{REFERENCES}

(1) Schwartz, M. Composite Materials Handbook; 2nd ed.; McGraw-Hill, Inc.: New York, 1992.

(2) Savage, G. Carbon-Carbon Composites; Chapman \& Hall: New York, 1993.

(3) Houdayer, M.; Gieres, J. S.; Tran-Van, D. U.S. Patent 4472454, September 18, 1984; Thurston, G. S.; Suplinskas, R. J.; Carroll, T. J.; Connors, D. F. Jr.; Scaringella, D. T.; Krutenat, R. C. U.S. Patent 5389152, February 14, 1995; and other patents pending.

(4) Brown, T. C.; King, K. D.; Nguyen, T. T. J. Phys. Chem. 1986, 90, 419.

(5) Tsang, W. Int. J. Chem. Kinet. 1978, 10, 1119.

(6) Berg, L.; Sumner, G. L. J.; Montgomery, C. W. Ind. Eng. Chem. 1945, 37, 352.

(7) Frey, F. E. Ind. Eng. Chem. 1934, 26, 198.

(8) Billaud, F.; Duret, M.; Elyahyaoui, K.; Baronnet, F. Ind. Eng. Chem. Res. 1991, 30, 1469.

(9) Korzun, N. V.; Magaril, R. Z.; Plyusnina, G. N.; Semukhina, T. I. Russ. J. Phys. Chem. 1979, 53, 631.

(10) Küchler, L. Trans. Faraday Soc. 1939, 35, 874.

(11) Levush, S. S.; Abadzkev, S. S.; Shevchuk, V. U. Neftekhimija 1969, 9, 716.

(12) Virk, P. S.; Korosi, A.; Woebcke, H. N. In Thermal Hydrocarbon Chemistry; Adv. Chem. Ser., 1979; 67.

(13) Aribike, D. S.; Susu, A. A.; Ogunye, A. F. Thermochim. Acta 1981, 51, 113.

(14) Larson, R. S.; Osterheld, T. H.; Allendorf, M. D., manuscript in preparation.

(15) Osterheld, T. H.; Allendorf, M. D.; Larson, R. S., work in progress.

(16) Keyser, L. F. J. Phys. Chem. 1984, 88, 4750.

(17) Cornu, A.; Massot, R. Compilation of Mass Spectral Data; $2^{\text {nd }}$ ed.; Heyden: Philadelphia, 1979; Vol. 1.

(18) Bittner, J. D.; Howard, J. B. Eighteenth Symposium (International) on Combustion, The Combustion Institute, 1981, 1105.

(19) Stein, S. E.; Fahr, A. J. Phys. Chem. 1985, 89, 3714. 


\section{UNLIMITED RELEASE}

Dr. Theodore M. Besmann

Oak Ridge National Laboratories

P.O. Box 2008

Oak Ridge, TN 37831-6063

Dr.F.D. Gac

G771

Los Alamos National Laboratory

P.O. Box 1663

Los Alamos, NM 87545

Dr. Greg Glaitzmaier

NREL

1617 Cole Blvd.

Golden, CO 80401

Dr. Suleyman A. Gokoglu

NASA Lewis Research Center

Mail Stop 106-1

Cleveland $\mathrm{OH} \quad 44135$

Dr. John W. Hastie

National Inst. of Standards \& Technology

Metallurgy Division

B106/223

Gaitherburg MD 20899

Dr. Gerd M. Rosenblatt

Building 50A, Room 4119

Lawrence Berkeley Laboratory

1 Cyclotron Road

Berkeley, CA 94720

Dr. Michael Zachariah

National Institute of Standards and Technology

Building 221, Rm. B312

Gaithersburg, MD 20899

Massachusetts Institute of Technology

Attn: N. Acharya, K.F. Jensen, Y. Xia

Building 6-469

Chemical Engineering

Cambridge, MA 02139

Dr. M. Khairul Alam

Associate Professor, Mechanical Engineering

Ohio University

Stocker Center 257

Athens, $\mathrm{OH} 45701$

Professor Richard Axelbaum

Washington University

St. Louis MO 63105

Dr. Simon H. Bauer

Cornell University

Department of Chemistry

Baker Laboratory

Ithica, NY 14853-1301
Dr. Ken Brezinsky

Department of Mechanical \& Aerospace Engineering

Princeton University

Engineering Quadrangle, D329

Princeton, NJ 08544

Professor Mark A. Capelli

Department of Mechanical Engineering

Stanford University

Building 500

Stanford CA 94305-1901

Professor John W. Daily

Department of Mechanical Engineering

University of Colorado

Boulder, CO 80309

Prof. David S. Dandy

Dept. of Agricultural and Chemical Engineering

Colorado State University

Fort Collins CO 80523

Professor Seshu B. Desu

Department of Materials Science and Engineering Virginia Polytechnic Institute

213 Holden Hall

Blacksburg VA 24061-0140

Professor Robert W. Dibble

Associate Professor, Mechanical Engineering

University of California

6159 Etcheverry Hall

Berkeley, CA 94720

Prof. James W. Evans

Dept. of Materials Science and Mineral Engineering

University of California

Berkeley CA 94720

Prof. Richard C. Flagan

Environmental Engineering

California Institute of Technology

138-78

Pasadena, CA 91125

Prof. Michael Frenklach

Dept. of Materials Science and Engineering

Pennsylvania State University

202 Academic Projects Building

University Park PA 16802

Prof. Bernard Gallois

Dept. of Materials Science

Stevens Institute of Technology

Castle Point on the Hudson

Hoboken, NJ 07030

Dr. Robert H. Hauge

Dept. of Chemistry

Rice University

Houston Texas 77251 
Professor D. Lynn Johnson

Chairman, Dept. of Materials Science \& Engineering

Northwestern University

The Technological Institute

Evanston, IL 60201

Professor Joseph L. Katz

Chemical Engineering

Johns Hopkins University

Charles and 34th Streets

Baltimore, MD 21218

Professor C. K. Law

Department of Mechanical \& Aerospace Engineering

Princeton University

P. O. Box CN 5263

Princeton, NJ 08544-5263

Prof. R.E. Mitchell

Dept. of Mechanical Engineering

Stanford University

Stanford CA 94305

Prof. Triantafillos J. Mountziaris

Chemical Engineering Dept.

SUNY Buffalo

Buffalo, NY 14260

Prof. Zuhair A. Munir

Department of Mechanical Engineering

University of California

Davis, CA 95616

Prof. S.E. Pratsinis

Chemical \& Nuclear Engineering

University of Cincinnati

627 Rhodes Hall, Mail Loc. 171

Cincinnati, OH 45221-0171

Prof. Daniel E. Rosner

Chemical Engineering Dept.

Yale University

P.O. Box 2159, Yale Station

New Haven CT 06520-2159

Prof. Robert J. Santoro

Department of Mechanical Engineering

Pennsylvania State University

313A Mechanical Engineering Building

University Park, PA 16802

Prof. Adel Sarofim

Department of Chemical Engineering

Massachusetts Institute of Technology

66-466

Cambridge, MA 02139
Prof. Brian W. Sheldon

Division of Engineering

Brown University

Box D

Providence RI 02912

Dr. Daniel J. Skamser

Dept. of Materials Science and Engineering

Northwestern University

MLSF 2036

Evanston II 60208-3108

Prof. Stratis V. Sotirchos

Dept. of Chemical Engineering

University of Rochester

Rochester, NY 14627-0166

Prof. Karl E. Spear

Dept. of Ceramic Science and Engineering

Pennsylvania State University

201 Steidle Building

University Park PA 16802

Prof. Thomas L. Starr

Room 113

Baker Building

Georgia Institute of Technology

Atlanta, GA 30332-0245

Textron Specialty Materials

Attn: T. Schoenberg, R.J. Suplinskas, G.S. Thurston

2 Industrial Avenue

Lowell, MA 01851

Ms. Wendy Foslien

Honeywell Technology Center

3660 Technology Drive

Minneapolis, MN 55418

Dr. J. L. Kaae

G.A. Technologies

P.O. Box 85608

San Diego, CA 92138

Dr. Meyya Meyyapan

Scientific Research Associates

50 Nye Road

P.O. Box 1058

Glastonbury, CT 06033

Dr. Sunil Shah

RelMan Incorporated

444 Castro Street, Suite 400

Mountain View, CA 94041 


\author{
MS0309 M. Lieberman, 9818 \\ MS0349 S. T. Picraux, 1112 \\ MS0457 R. J. Eagan, 5600 \\ MS0601 W. G. Breiland, 1126 \\ MS0601 M. E. Coltrin, 1126 \\ MS0601 P. Esherick, 1126 \\ MS0601 P. Ho, 1126 \\ MS0702 D. E. Arvizu, 6200 \\ MS0710 G. A. Carlson, 6211 \\ MS 1349 R. E. Loehman, 1808 \\ MS1393 D. W. Schaefer, 1814 \\ MS9001 J. C. Crawford, 8000 \\ Attn: $\quad 8200$ R. J. Detry \\ 8400 L. A. Hiles \\ MS9042 R. J. Kee, 8745 \\ Attn: E. Evans \\ W. G. Houf \\ MS9042 S. Griffiths, 8745 \\ MS9042 R. Nilson, 8745 \\ MS9042 R. Larson, 8745 \\ MS9042 E. Meeks, 8745 \\ MS9052 M. D. Allendorf, 8361 (10) \\ MS9052 D. R. Hardesty, 8361 (5) \\ MS9052 T. H. Osterheld, 8361 \\ MS9054 W. J. McLean, 8300 \\ Attn: $\quad 8302$ W. Bauer \\ 8355 G. Fisk \\ 8362 R. Carling \\ 8366 C. Hartwig \\ MS9055 F.P. Tully, 8353 \\ MS9161 W. G. Wolfer, 8341 \\ MS9161 R. H. Stulen, 8342 \\ MS9162 D. A. Outka, 8347
}

MS9162 A.E. Pontau, 8347

MS9214 C. F. Melius, 8117

MS9401 R. C. Wayne, 8700

Attn: $\quad 8702$ C. W. Robinson

8712 M. I. Baskes

8713 J. M. Hruby

8713 M. C. Nichols

8714 M.W. Perra

8716 R. E. Stoltz

MS9021 Technical Communications Department 8535 , for OSTI (10)

MS9021 Technical Communications Department 8535/Technical Library, MS0899, 13414

MS0899 Technical Library, 13414 (4)

MS9018 Central Technical Files, 8523-2 (3) 